\title{
Spatiotemporal Characteristics of Drought Occurrences over Japan
}

\author{
SANG-Min LEE AND HI-RYONG ByUN \\ Department of Environmental Atmospheric Sciences, Pukyong National University, Busan, South Korea \\ HIROSHI L. TANAKA \\ Center for Computational Sciences, University of Tsukuba, Tsukuba, Japan
}

(Manuscript received 2 August 2011, in final form 1 January 2012)

\begin{abstract}
The drought climate of Japan from 1902 to 2009 was analyzed using an effective drought index (EDI). Drought regions were identified by hierarchical cluster analysis using drought characteristics (duration, severity, and onset and end dates) obtained from 50 observation stations. The results indicated that droughts could be divided into four groups (G1-G4) that reflected the local climate. The four groups were related to precipitation as follows. The summer rainy season affected groups G2-G4, in which droughts occurred mainly during spring and summer and were relieved before and after the rainy season. The G1 group was not affected by the summer rainy season and droughts were spread evenly throughout the year; it even had cases of droughts relieved by winter snow. All groups included dry conditions over the 108 -yr period, and the driest conditions occurred in the late twentieth century. The statistical analysis of drought data showed that a total of 23 country-wide droughts occurred and that the most extreme droughts occurred in 1939-41 and 1984-85, with an EDI of -1.55. In addition, four dry seasons (1939-45, 1997-98, 1994-97, and 2005-09) were found using regime shift analysis. Regional droughts occurred 54, 54, 49, and 59 times in groups G1-G4, respectively. On average, short-term droughts with a duration shorter than 6 months occurred 3.5 times per decade, whereas long-term droughts extending over $1 \mathrm{yr}$ occurred 0.3 times per decade. The drought duration and intensity were used to calculate the statistical return period of country-wide droughts. The 1939-41 drought had the longest return period, at $104.7 \mathrm{yr}$. The 1987-88 and 1995-97 droughts had return periods of 65.9 and $65.5 \mathrm{yr}$, respectively.
\end{abstract}

\section{Introduction}

The Japanese region has abundant rainfall and it is characterized by a rainy summer season ("baiu") and annual typhoons. However, most rivers in Japan have a high river-mouth altitude near the ocean, with steeper slopes than do rivers in other countries with flatter terrain (Takahashi and Sakaguchi 1976). Therefore, rainwater falling in the mountain ranges flows quickly to the ocean, resulting in the Japanese region using only a limited amount of rainwater (approximately $1 / 4$ of the world average).

Owing to its topographical conditions, Japan, like other Asian countries, has experienced repeated water shortages in the past (e.g., 1939, Lake Biwa; 1964 during

Corresponding author address: Prof. Hi-Ryong Byun, Dept. of Environmental Atmospheric Sciences, Pukyong National University, Busan 608-737, South Korea.

E-mail: hrbyun@pknu.ac.kr the Tokyo Olympics; 1967, Nagasaki; 1973, Takamatsu; and 1978, Fukuoka). Recently, in 1994, most regions in Japan experienced water shortages. During this period, the water quality of major rivers (Lake Sagami, Tsukui, and Tanzawa) deteriorated and the water supply had to be regulated (Taniyama 2002). Locally, ground sedimentation occurred owing to the overuse of underground water (Yamamoto 1995; Gleick et al. 2002). Furthermore, approximately 16 million people experienced watersupply suspension or water-saving restrictions at least once, and the country suffered an economic loss worth around $¥ 140$ billion as a result of the resulting decline in agricultural production (Japan Water Agency 2010).

Water shortages can be caused by a rapid increase in demand and by human overuse; however, in most cases, they are caused by severe droughts. The water shortage in the Tokyo region in 1964 was caused by the severe drought that occurred in 1964-65 (IDI 1998), rapid population growth due to the urbanization of the Tokyo region after the Second World War, and a rapid 


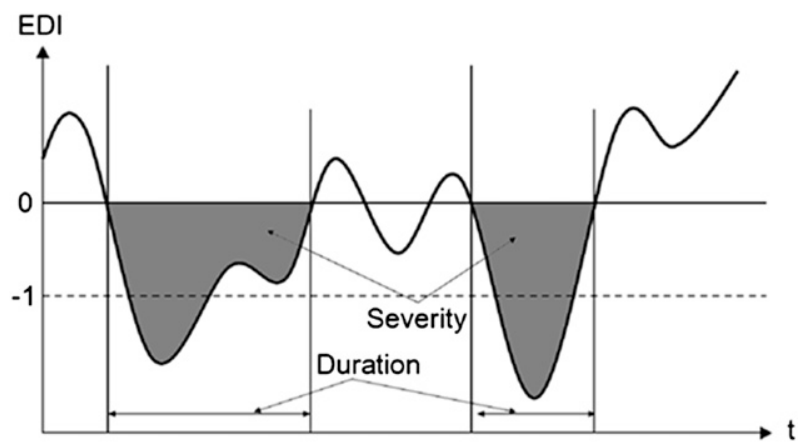

FIG. 1. Definition of drought events and properties using EDI.

increase in water demand during the Olympics (Takahasi and Uitto 2004; Takahasi 2009). However, except for the water shortage in 1964, all of the other water shortages were caused by severe droughts.

Although Japan has repeatedly faced serious water shortages owing to severe droughts, studies on droughts are rarely found in the literature. This may be because of the rainfall pattern in Japan, which is thought to relieve droughts in a short period of time. This further implies that securing water resources is not considered to be a problem because of Japan's three rainy seasons (the summer rainy season, the baiu; the fall rainy season, the shurin; and the continuous rainfall in spring), as well as summer typhoons and winter snow.

In reality, even though securing water resources is not always easy and water shortages do occur occasionally, the problem of water shortage does not attract much interest in Japan. The damage due to droughts in Japan, along with damage due to typhoons, heavy rain, and cool summers, has become a major cause of economic losses (Uemera et al. 1974). Therefore, it is important to gain an overall understanding of Japan's past droughts.

In the past, studies on the overall drought climate have appeared in international publications (Huff and Changnon 1963; Chowdhury and Abhyankar 1984; Karl and Heim 1990; Soulé 1993; Lloyd-Hughes and Saunders 2002; Sönmez et al. 2005; Trnka et al. 2009). These studies have quantified drought severity by using the Palmer drought severity index (PDSI; Palmer 1965) and the standardized precipitation index (SPI; McKee et al. 1993). Spectral analysis (Bhalme and Mooley 1981; Cook and Jacoby 1983; Meko et al. 1985; Jiang et al. 2006; Wang et al. 2007) and principal component analysis (Klugman 1978; Karl and Koscielny 1982; Murata 1990; Bonaccorso et al. 2003) were used to analyze the drought occurrence cycle. These studies have a number of unresolved problems. The PDSI, for example, is inaccurate in calculating soil moisture (Wang et al. 2007) and involves a complicated procedure. In addition, originally developed for

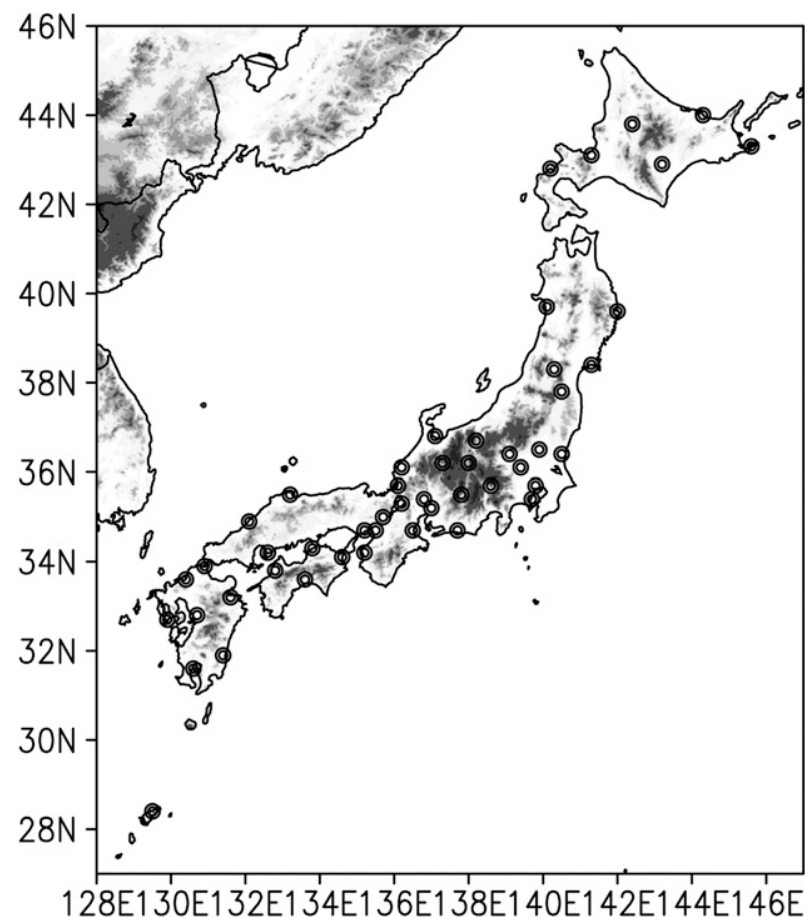

FIG. 2. Locations of 50 observation stations in Japan. Shaded area indicates topography. Precipitation records from all stations for 1901-2009 were available.

the U.S. Great Plains, PDSI is not suitable for mountainous regions (Alley 1984; Karl 1987; Guttman 1998; Heddinghaus and Sabol 1991; Wilhite 1983). On the other hand, the use of SPI involves complications in objectively setting the base period (Byun and Wilhite 1999). Kim et al. (2009) have pointed out the disadvantages of using the sliding time scale. The use of other analyses such as spectrum analysis and principal component analysis involves problems in analyzing both droughts and floods simultaneously and they use all the precipitation data collected during the analysis period, and not just maximum or minimum values (Byun et al. 2008).

In this study, the effective drought index (EDI) was used for quantifying the drought severity in Japan. The EDI is initially used to calculate the amount of available water resources by considering the rainfall loss per unit time, using daily rainfall data, and then compares this resource amount with the daily average for standardization. This index offers the advantage of accurately determining the drought onset and end dates, along with the daily drought index. The EDI has been used in several studies for drought analysis (Byun et al. 2008; Kang and Byun 2004; Kim and Byun 2006; Kim et al. 2011; Lee and Byun 2009). For example, Morid et al. (2006) and Pandey et al. (2007) have suggested that the EDI is better than other drought indices such as SPI for monitoring droughts in Iran and India because it shows the availability and 
a)

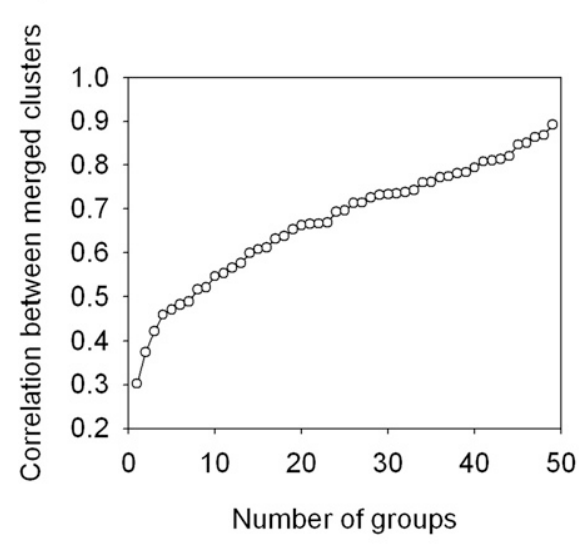

b)

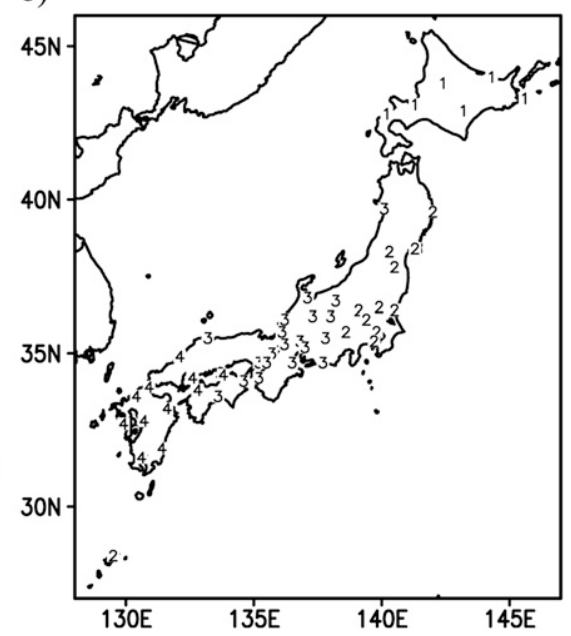

FIG. 3. Cluster analysis from monthly minimum EDI (1902-2009). (a) Between-groups correlation for monthly minimum EDI. The number of divisions ranges from 1 to 49 . (b) Spatial distribution of drought clusters.

deficiency of water resources better than do other indices and accurately calculates the drought onset and end dates, the daily drought index, and the weight of rainfall loss per unit time.

This study is divided into four sections. In section 2, we present the data and method used for the analysis. Section 3 describes the spatiotemporal characteristics of regional and national droughts in Japan, and in section 4 , the drought return period is discussed on the basis of the duration and intensity of droughts. The summary and conclusions are presented in section 5 .

\section{Data and methods}

\section{a. Effective drought index}

The EDI is calculated using the following three equations:

$$
\begin{aligned}
\mathrm{EP} & =\sum_{n=1}^{i}\left[\left(\sum_{m=1}^{n} P_{m}\right) / n\right], \\
\mathrm{DEP} & =\mathrm{EP}-\mathrm{MEP},
\end{aligned}
$$

and

$$
\mathrm{EDI}=\mathrm{DEP} / \mathrm{ST}(\mathrm{DEP})
$$

where EP, DEP, and MEP denote the effective precipitation, the deviation of EP, and the mean of EP, respectively. The quantity $P_{m}$ indicates the precipitation on $m$ previous days. The index $i$ (duration of summation) in Eq. (1) is 365 (i.e., the annual period). Therefore, in order to calculate the EDI for 1 day, the minimum data required are the previous 365-day rainfall data. MEP in Eq. (2) and ST(DEP) in Eq. (3) are the long-term average and the standard deviation of each day's DEP, respectively. When a negative DEP is calculated for more than 2 days, the combined period $i$ becomes larger than the unlimited continuing period. The "drought range" of the EDI indicates extreme drought at EDI $\leq-2.0$, severe drought at $-2.0<$ EDI $\leq-1.5$, and moderate drought at $-1.5<$ EDI $\leq-1.0$. Near-normal conditions are indicated by $-1.0<$ EDI $<1.0$.

\section{b. Definition and concept of drought}

A drought was defined to occur, as illustrated in Fig. 1, when the EDI values were less than -1.0. The drought onset date was determined to be the day on which the EDI first showed a negative value, and the end date was determined to be the day prior to that on which the EDI regained a positive value. Drought durations are the time periods between the onset and the end date, and the shaded area in Fig. 1 indicates the drought severity. This study only considers the meteorological drought in Japan because the EDI is calculated using only rainfall data.

\section{c. Rainfall data}

The rainfall data used in the EDI calculations were taken from 50 observatories (Fig. 2) by the Japan Meteorological Agency over a 109-yr period (i.e., 1901-2009). The national and regional (regional groups represent the four drought areas; see Fig. 3b for their locations) mean rainfall time series were used to calculate a 15-day 


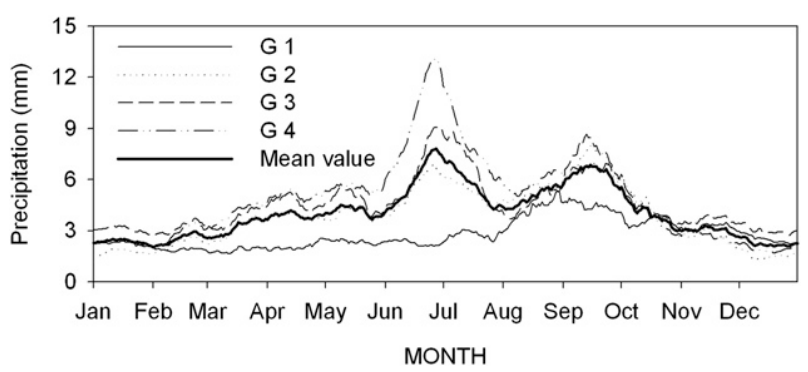

FIG. 4. Variation in 15-day running mean of precipitation averaged from 1971 to 2000 for the four groups and the overall national total.

running mean in order to remove short-period variations (Fig. 4). The rainfall cycle of Japan averaged over these 50 stations clearly shows that the highest rainfall occurs during the baiu season - the summer rainy season from the end of May to the end of July_ and during the shurin season-the autumn rainy season from the end of July to the end of October. The spring rainy season experienced by Korea and China did not appear clearly in the Japanese data, which showed only three small peaks from early February to the end of May.

\section{d. Analysis methods}

The drought climate data were first organized by classifying the 50 stations in Japan into national and regional groups that had similar drought characteristics; these groups formed the basis of our analysis. The basic drought occurrence statistics-the individual timing of each drought-were then investigated. Next, we produced a drought rose, in order to easily view the drought onset and end dates for each group, and a drought map of the drought onset history using the method proposed by Kim et al. (2011). Finally, the distribution of drought onset and end dates was compared with the average rainfall distribution for each group, and the statistical drought return period was calculated.

The statistical drought return period is usually calculated using extreme event analytical methods used in hydrology and water resource engineering. The concept of a return period, in terms of drought-related variables, refers to the average time between events with a certain threshold (Haan 1977). For droughts, a significant correlation can be obtained by considering drought characteristics (duration, magnitude, and severity) for multivariable events for which the duration, magnitude, and severity are given. Therefore, the drought duration, scale, severity, and other parameters must be obtained in order to calculate the drought return period. Shiau and Shen (2001) have proposed the joint distribution of drought duration and severity with an improved method for analyzing drought characteristics. The frequencyanalysis-related drought occurrence is primarily based on the estimation of the probability density function (PDF) (Kim et al. 2003). The PDF can be determined by parametric and nonparametric methods. As there is no universally accepted distribution for hydrological variables (Silverman 1986; Moon and Lall 1994; Smakhtin 2001), two estimations can be used for each sample distribution. In this study, we calculated the return period by using the parametric method for estimating the PDF, as suggested by Kim et al. (2003), and we also considered the effect of the drought duration and severity on the return period.

\section{Spatiotemporal characteristics of droughts}

\section{a. Drought subregions}

Because Japan spans a wide latitude range, with a distance of approximately $3000 \mathrm{~km}$ between the northern and the southern islands, it experiences a variety of climates. Before analyzing the drought climate, it is necessary to distinguish these climatic regions using EDI quantification. Therefore, a hierarchical cluster analysis was performed using drought characteristics (i.e., duration, severity, onset and end dates) as the base. To measure the drought similarities between multiple regions, the meteorological drought-based similarity index (SI),

TABLE 1 . Number of national and regional droughts by severity and duration.

\begin{tabular}{|c|c|c|c|c|c|c|}
\hline & & T-EDI & G1-EDI & G2-EDI & G3-EDI & G4-EDI \\
\hline & 50 & 6 & 12 & 20 & 12 \\
\hline \multicolumn{2}{|c|}{ Total No. of droughts } & 23 & 54 & 54 & 49 & 59 \\
\hline \multirow[t]{3}{*}{ Severity } & Moderate & 21 & 46 & 48 & 37 & 47 \\
\hline & Severe & 2 & 6 & 6 & 12 & 10 \\
\hline & Extreme & - & 2 & - & - & 2 \\
\hline \multirow[t]{5}{*}{ Duration } & $D \leq 90$ days & 5 & 16 & 18 & 21 & 23 \\
\hline & $90<D \leq 180$ days & 8 & 24 & 21 & 15 & 15 \\
\hline & $180<D \leq 360$ days & 4 & 10 & 14 & 8 & 17 \\
\hline & $360<D \leq 720$ days & 6 & 4 & 1 & 5 & 4 \\
\hline & $\left(\mathrm{km}^{2}\right)$ & 325892 & 83452 & 77368 & 96376 & 68696 \\
\hline
\end{tabular}


TABLE 2. Frequency and percentage of drought occurrence and severity over all stations. Also shown are the frequency of occurrence per one station and the annual mean drought occurrence frequency per one station.

\begin{tabular}{lrrcr}
\hline \hline Drought severity & No. & \multicolumn{1}{c}{$\%$} & One station & $1 \mathrm{yr}$ \\
\hline Moderate & 3112 & 64.6 & 62.24 & 0.57 \\
Severe & 1241 & 25.8 & 24.82 & 0.23 \\
Extreme & 465 & 9.6 & 9.30 & 0.09 \\
Total & 4818 & 100.0 & 96.36 & 0.89 \\
\hline
\end{tabular}

proposed by Dezfuli et al. (2010), was used. The SI calculates the drought duration and severity for all the regions, and the concordance rate is calculated to assign weights to the duration and severity and determine the similarity between regions. In this study, identical weights of 0.5 were assigned to each of these parameters and the total weight for the duration and severity was 1 . The SI represents the degree of average similarity among all the stations after it averages the degree of similarity between each station. The calculated SI was used in the hierarchical cluster analysis performed using the between-group linkage method (Fig. 3a), and, as a result, four groups were identified (Fig. 3b). Group 1 (G1) is Hokkaido, group 2 (G2) is the east coast of Honshu, group 3 (G3) is the west coast of Honshu with a certain part of Shikoku, and group 4 (G4) contains certain parts of Kyushu and Shikoku. Table 1 lists the number of stations in each group. We denote the average EDI over all 50 stations as T-EDI, and the average EDIs for each of the groups G1-G4 are denoted as G1-EDI-G4-EDI, respectively.

\section{b. Severity and duration distribution}

The calculated EDI for each station was used to organize the frequency of droughts on the basis of severity and duration for the analysis period (Table 1). T-EDI indicated 23 droughts among which 21 were moderate and 2 were severe; however, no extreme droughts were found. The groups G1-G4 had 54, 54, 49, and 59 droughts, respectively. Most of the droughts were moderate and only groups G1 and G4 had extreme droughts. In terms of duration, short-term droughts lasting less than 180 days represented $70 \%$ of the droughts in all the groups (3.5
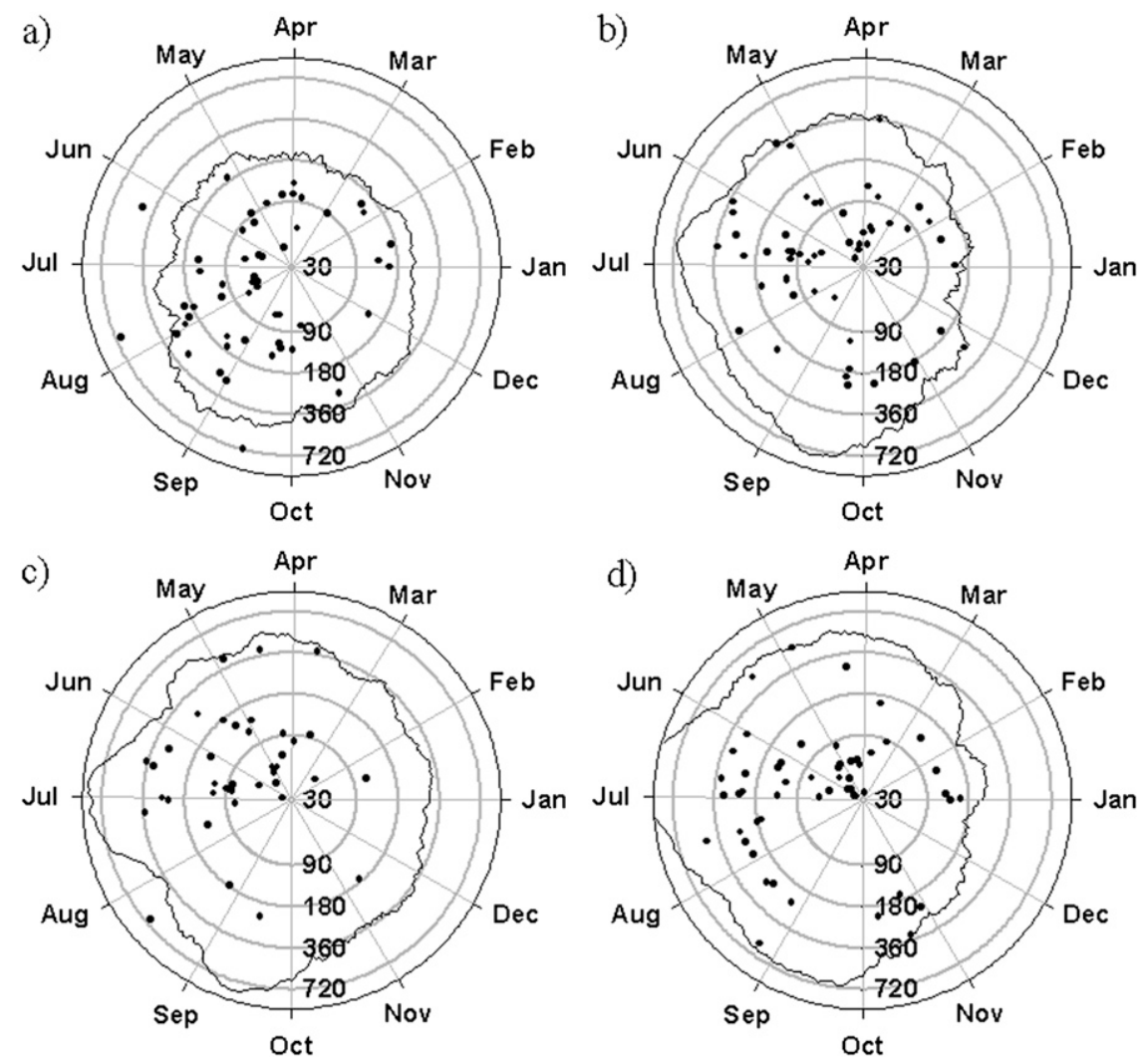

FIG. 5. Scatterplot of drought onset date against drought duration for droughts recorded at (a) G1-EDI, (b) G2-EDI, (c) G3-EDI, and (d) G4-EDI. Each radial axis denotes the first day of the month. 

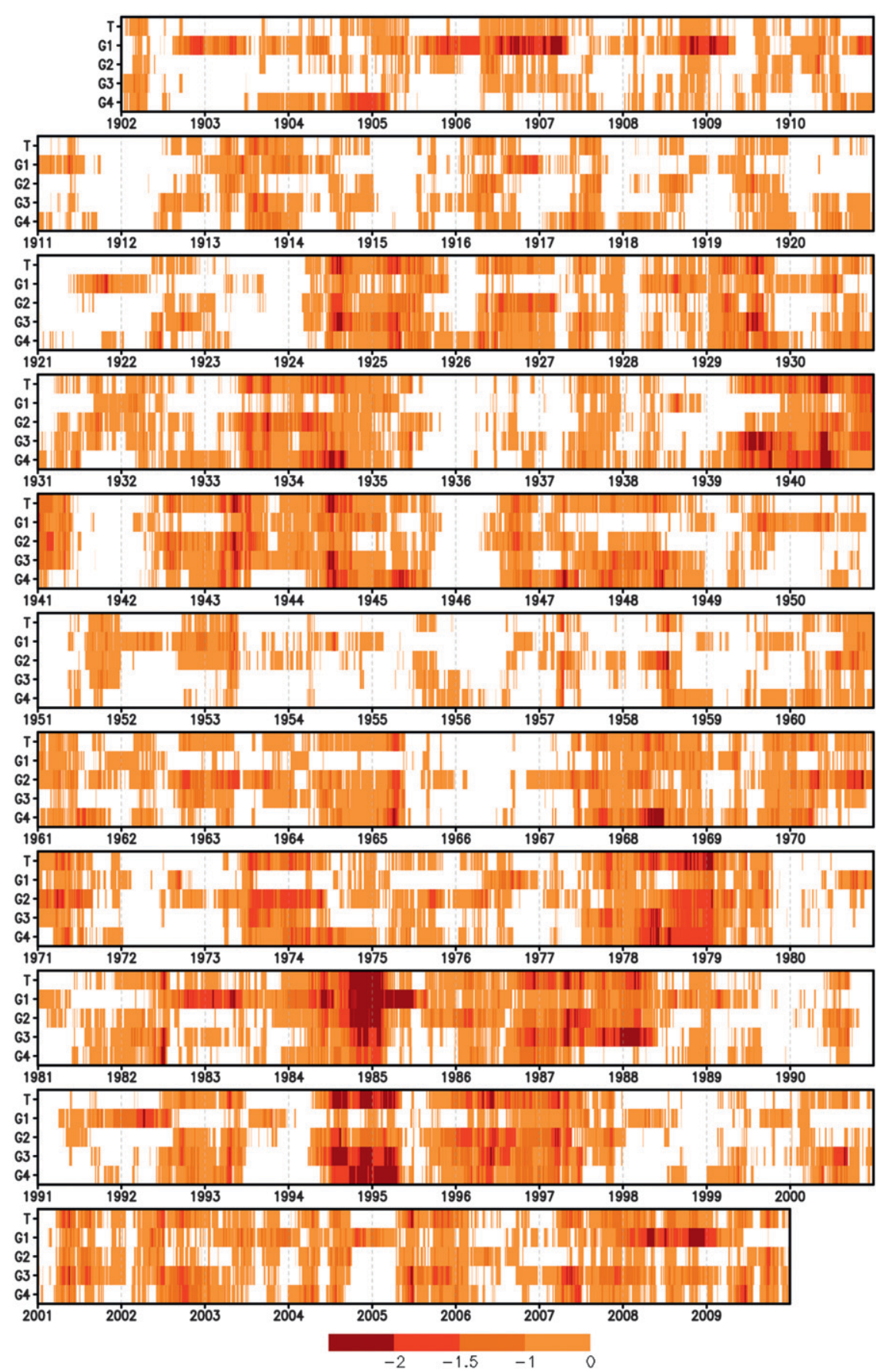

FIG. 6. (top to bottom) Historical drought map (EDI) from1902 to 2009. The T and G1-G4 labels denote the averaged EDI over national and group droughts, respectively.

times/decade), whereas long-term droughts lasting more than one year composed only $7 \%$ of the droughts during the entire period ( 0.3 times/decade). When the 50 stations were considered separately (Table 2 ), $9.6 \%$ of all the droughts were extreme with an average occurrence rate of 9.3 per station. The total average showed that any station in Japan had droughts occurring approximately 0.89 times per year.

There is a high frequency of short-term droughts in Japan because there are three rainy seasons, as shown by the daily average rainfall distribution (Fig. 4); thus, droughts often cannot last for a long period. G4 has the 
TABLE 3. Onset and end dates and durations of historical national droughts. Also listed are the minimum values and dates of T-EDI, and the station numbers with the minimum EDIs among all stations.

\begin{tabular}{|c|c|c|c|c|c|c|c|}
\hline No. & Onset date & End date & Duration (days) & Min T-EDI & Date of min EDI & Min EDI & No. of stations \\
\hline 1 & 14 Jun 1924 & 17 Aug 1925 & 428 & -1.12 & 17 Aug 1924 & -2.56 & 47759 \\
\hline 2 & 8 Jun 1929 & 30 Sep 1929 & 113 & -1.14 & 9 Aug 1929 & -2.48 & 47759 \\
\hline 3 & 2 Jun 1933 & 20 Oct 1933 & 139 & -1.08 & 5 Oct 1933 & -2.68 & 47662 \\
\hline 4 & 5 Feb 1934 & 20 Jun 1934 & 134 & -1.04 & 15 Jun 1934 & -2.78 & 47637 \\
\hline 5 & 16 May 1939 & 14 Mar 1941 & 666 & -1.55 & 14 Jun 1940 & -4.76 & 47616 \\
\hline 6 & 15 Feb 1943 & 18 Jun 1943 & 122 & -1.40 & 14 May 1943 & -2.88 & 47618 \\
\hline 7 & 20 Jun 1943 & 20 Sep 1943 & 91 & -1.02 & 1 Jul 1943 & -2.51 & 47618 \\
\hline 8 & 13 May 1944 & 8 Oct 1944 & 147 & -1.34 & $18 \mathrm{Jul} 1944$ & -2.96 & 47759 \\
\hline 9 & 15 Jun 1958 & 2 Aug 1958 & 47 & -1.10 & 18 Jul 1958 & -2.63 & 47670 \\
\hline 10 & 16 Nov 1964 & 3 May 1965 & 167 & -1.02 & 12 Apr 1965 & -3.36 & 47654 \\
\hline 11 & 10 Jun 1973 & 8 Apr 1974 & 301 & -1.02 & 25 Jul 1973 & -2.54 & 47742 \\
\hline 12 & 27 Aug 1977 & 23 Jun 1978 & 299 & -1.18 & 15 May 1978 & -2.85 & 47759 \\
\hline 13 & 25 Jun 1978 & 2 Apr 1979 & 280 & -1.24 & 24 Jan 1979 & -2.56 & 47766 \\
\hline 14 & 7 Jun 1982 & 1 Aug 1982 & 54 & -1.12 & 6 Jul 1982 & -2.27 & 47637 \\
\hline 15 & 20 Mar 1984 & 19 Mar 1985 & 363 & -1.55 & 9 Dec 1984 & -3.39 & 47421 \\
\hline 16 & 16 Aug 1986 & 24 Mar 1987 & 219 & -1.12 & 11 Dec 1986 & -2.40 & 47909 \\
\hline 17 & 25 Mar 1987 & 7 May 1988 & 407 & -1.37 & 10 May 1987 & -3.13 & 47610 \\
\hline 18 & 16 Mar 1993 & 2 May 1993 & 46 & -1.11 & 21 Apr 1993 & -2.30 & 47632 \\
\hline 19 & 29 Apr 1994 & 12 May 1995 & 377 & -1.43 & 10 Aug 1994 & -2.90 & 47770 \\
\hline 20 & 25 Apr 1995 & 6 Apr 1997 & 557 & -1.19 & 6 Jun 1996 & -2.58 & 47654 \\
\hline 21 & 9 Apr 1997 & 10 Jul 1997 & 91 & -1.02 & 7 May 1997 & -2.70 & 47893 \\
\hline 22 & 1 Apr 2001 & 19 Jun 2001 & 78 & -1.10 & 20 May 2001 & -2.53 & 47617 \\
\hline 23 & 11 May 2005 & $10 \mathrm{Jul} 2005$ & 59 & -1.18 & 26 Jun 2005 & -2.90 & 47770 \\
\hline
\end{tabular}

lowest annual mean rainfall among the four groups and it has one rainfall peak at the end of August. It also experiences the effect of the summer monsoon later than the other groups and has a different rainfall pattern. Therefore, the drought climate of G4 appears to be different from that of the other groups.

\section{c. Seasonal characteristics}

Figure 5 shows the drought roses (the angle indicates the drought onset date; the radius represents the drought duration) for the four groups, along with their annual average rainfall (solid line, 15-day running mean $\times 100$; Kim et al. 2011). The short-term droughts (with durations less than 180 days) in G1 were distributed evenly through the year, whereas those in G2-G4 occurred in spring and summer. For G1, the mid- and long-term droughts with durations greater than 180 days occurred mainly in August, the highest rainfall season, whereas for G2-G4, long-term droughts occurred mainly in June, the high rainfall season. These observations suggest that the shortterm droughts were caused by insufficient rainfall during the three rainy seasons, whereas the mid- and long-term droughts were caused by insufficient rainfall during the baiu season.

All the groups showed similar drought relief during the three rainy seasons. It is interesting to note that in G1, drought relief occurs during winter. This fact implies that melting snow owing to rising temperatures, rather than rainfall, is responsible for relieving droughts in winter. Therefore, it is necessary to further investigate the correlation between snow and drought relief.

\section{d. Drought map}

The T-EDI data were used to draw a drought map summarizing the severity and duration of droughts in Japan for the period 1902-2009 (Fig. 6; Kim et al. 2011). Both T-EDI and G1-G4-EDI were standardized using the variability of the analyzed period as the base. The details of 23 drought occurrences (onset and end dates, duration, severity, and minimum EDI) are listed in Table 3 with T-EDI as the base. The most extreme drought in recorded history lasted for 666 days and began in May 1939 and ended in March 1941. The second and third longest droughts occurred in September 1995 and June 1924 and lasted for 557 and 428 days, respectively. In terms of intensity, the droughts occurring in March 1984 (EDI of -1.55) and April 1994 (EDI of -1.43 ) were the most severe.

The 1990s had the longest dry period; between April 1994 and July 1997, except for 5 months in 1995 (MaySeptember), was a continuously dry period. In addition, all four groups experienced a gradual rise in dry conditions over $108 \mathrm{yr}$ and experienced their driest conditions in the late twentieth century. An exception to this trend was the 1950 s, which had relatively few droughts. 


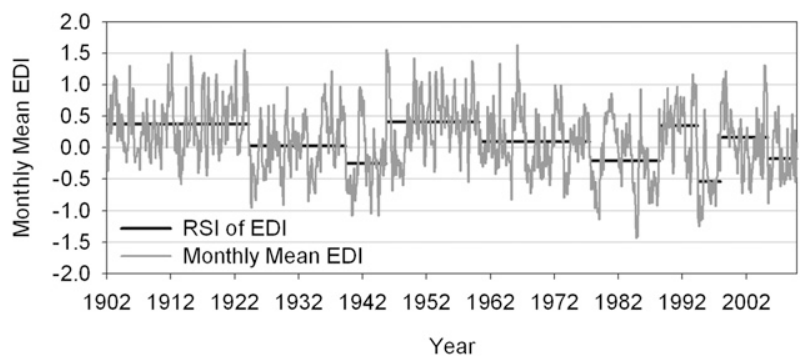

FIG. 7. Time series of the monthly mean EDI (solid gray curve) from 1902 to 2009. Solid black lines indicate regime shifts calculated using the sequential method (version 3.2; Rodionov 2006) with the threshold significance level $p=0.1$, cutoff length $l=10 \mathrm{yr}$, and Huber's weight parameters set to 6 .

In terms of individual groups, G1 shows dry periods that are different from the dry periods in G2-G4; this observation can be explained by the different drought climates of the groups. A drought occurred in G1 in the late 1940s during the most extreme drought period (May 1939-March 1941). Further, G2-G4 experienced a drought during the period April 1994-May 1995; however, G1 did not experience a drought in this period. On the other hand, only G1 showed a number of dry periods in the early 1900s. As discussed earlier, the rainfall pattern in $\mathrm{G} 1$ is different and is frequently affected by winter snow; thus, the drought onset and end dates of G1 are different from those of G2-G4. The frequency of droughts on a country-wide basis averaged 2.1 times decade per; however, in G1-G4, the droughts occurred 5.0, 5.0, 4.5, and 5.5 times per decade, respectively.

\section{e. Long-term variation in droughts}

To analyze the long-term variation trend, the sequential method (version 3.2; Rodionov 2006) was applied to the monthly T-EDI results for analyzing the regime shift over the 108-yr period (Fig. 7). This method uses a sequential $t$ test that can statistically detect significant shifts in the mean within a time series (Rodionov 2006). The threshold significance severity $p$ was 0.1 , the cutoff length $l$ was $10 \mathrm{yr}$, and Huber's weight parameters were set to 6.

Four dry seasons were found from 10 regime shifts. The driest season was from May 1994 to November 1997, and the second driest season was from May 1939 to May 1945. The third driest season was from July 1977 to May 1988 (i.e., a period of over $10 \mathrm{yr}$ ). The final dry season was from May 2005 to December 2009; this dry trend continues to the current period. This tendency is clearly shown in the deviation of the annual rainfall from the average (Fig. 8). The results of the rainfall deviation calculation for the period 1971-2000, with an averaged normal precipitation of $1560.7 \mathrm{~mm}$, show that

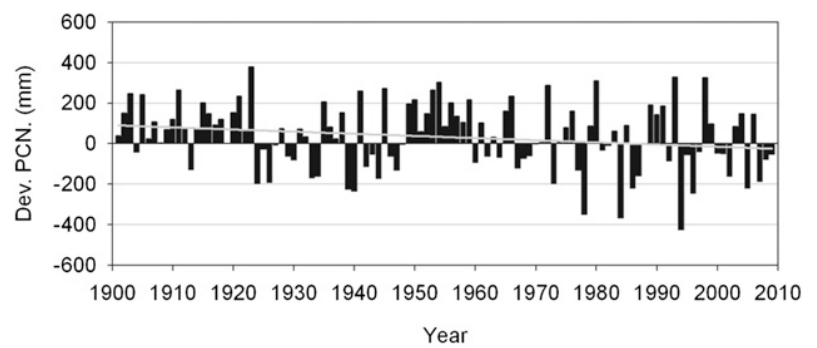

FIG. 8. Deviation in precipitation from 1901 to 2009. Normal value of precipitation is $1560.7 \mathrm{~mm}$. Gray solid line represents the linear trend of precipitation.

the negative deviation period accurately reflects the dry tendency of the EDI. Furthermore, a linear trend analysis shows that rainfall tends to decrease toward the late twentieth century; this result is in agreement with the drought map (Fig. 6). This decrease in rainfall was also accompanied by a considerably higher variability in rainfall than that in previous years.

\section{Return period}

\section{a. Drought severity and duration in Japan}

Figure 9a is a scatter diagram showing the severity and duration of each drought recorded in Japan. The severity of the drought increases with an increase in the drought duration. This can be clearly observed in the joint probability distribution shown in Fig. 9b. In Japan, short-term droughts lasting less than 90 days are less severe and have a higher occurrence rate than those lasting more than 90 days. A similar study of drought duration and frequency distribution versus severity in arid regions showed results with two peaks (Kim et al. 2003). This study, however, shows that for Japan, the drought duration and severity distribution has only one peak. As previously stated, the frequency of droughts lasting more than $1 \mathrm{yr}$ was very low. The frequency of droughts lasting less than 90 days was $56 \%$ - slightly over half-and that of droughts lasting less than 180 days was approximately $80 \%$. Therefore, most droughts in Japan are short-term droughts, and long-term droughts lasting longer than 6 months account only for approximately $20 \%$ of the total number of droughts.

\section{b. Return period of country-wide drought}

The statistical return period for country-wide droughts in Japan was calculated using the method proposed by Kim et al. (2003). If variables are assumed to be distributed identically and independently (Chow et al. 1988), the return period of an event in any observation is the inverse of its exceedance probability: 
a)

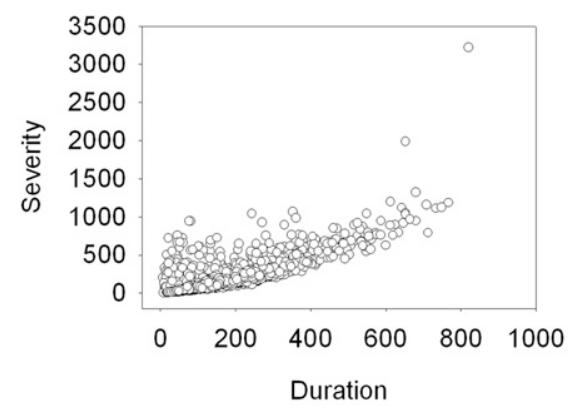

b)

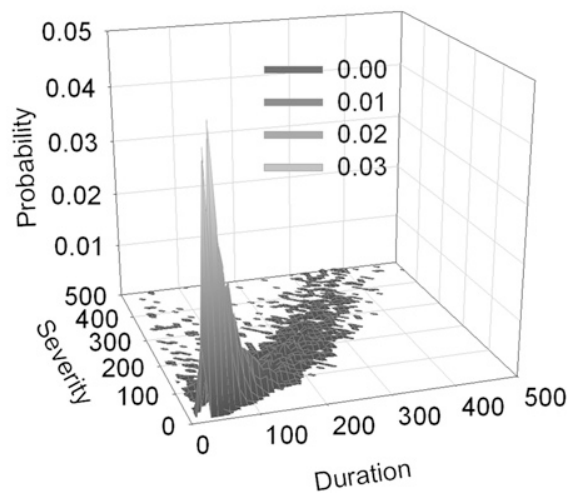

FIG. 9. (a) Scatter distribution and (b) joint probability of drought duration and severity.

$$
\begin{aligned}
& p=P\left(X>x_{T}\right) ; \text { i.e., } \\
& T=\frac{1}{P\left(X>x_{T}\right)}=\frac{1}{1-P\left(X \leq x_{T}\right)},
\end{aligned}
$$

where $x_{T}$ is the scale of the event with return period $T$.

Because droughts occasionally last for more than $1 \mathrm{yr}$, drought characteristics can be analyzed with a partial duration series; the distribution for partial duration series of independent events should be converted to an equivalent distribution for an annual exceedance series using the peak-over-threshold or partial-duration-series methods (Eagleson 1972; Willems 2000). If the surrounding cumulative distribution of drought cycle $d$ is defined as $F_{D}(d)$ for the given threshold, the return period $T_{d}$ of the drought cycle can be defined, using Eq. (2), as

$$
T_{d}(\text { years })=\frac{N}{n\left[1-F_{D}(d)\right]}=\frac{1}{\theta\left[1-F_{D}(d)\right]}
$$

where $\theta=n / N, N$ is the total length of the EDI observation period (yr), and $n$ is the total number of drought events $d$ during period $N$.

To find $F_{D}(d)$, appropriate frequencies were estimated for the observed drought durations. The results of a goodness-of-fit calculation using the parametric method for obtaining the PDF are listed in Table 4. As stated in section $4 \mathrm{a}$, droughts in Japan, unlike those in other countries, have only one peak; hence, the parametric method was used to estimate the most appropriate model from the Anderson-Darling and chi-square tests. The results showed that the three-parameter inverse Gaussian distribution was the most appropriate distribution. The PDF is given by

$$
f(x)=\sqrt{\frac{\lambda}{2 \pi(x-\gamma)^{3}} \exp \left[-\frac{\lambda(x-\gamma-\mu)^{2}}{2 \mu^{2}(x-\gamma)}\right]},
$$

where $\lambda=125.29, \mu=116.06$, and $\gamma=-0.59432$.

The bivariate return period of a drought can be estimated by substituting the univariate cumulative density function (CDF) into the bivariate CDF (Kim et al. 2003). Thus, the drought duration and severity, given the return period, can be calculated from

$$
T_{d, i}=\frac{1}{\theta\left[1-F_{D, I}(d, i)\right]},
$$

where $T_{d, i}$ is the joint return period of drought duration and intensity and $F_{D, I}(d, i)[=P(D \leq d, I \leq i)]$ is the joint cumulative distribution of drought duration and intensity.

The return periods for country-wide droughts in Japan, calculated using Eq. (7), are shown in Fig. 10. The drought that occurred from May 1939 to March 1941 has a 104.7-yr return period and was found to be the most extreme drought. This drought began in G4 and gradually expanded to G3, G2, and G1. The drought map (Fig. 6) shows that it was relieved simultaneously in all the groups by the rainfall in March 1941. Subsequent droughts during March 1987-May 1988 (minimum EDI of -1.37) and September 1995-April 1997 (minimum EDI of -1.19) had return periods of 65.9 and $65.5 \mathrm{yr}$, respectively, and were found to be even more extreme

TABLE 4. Results of goodness-of-fit calculations.

\begin{tabular}{lcllc}
\hline \hline \multicolumn{2}{c}{ Anderson-Darling } & & \multicolumn{2}{c}{ Chi-square } \\
\cline { 1 - 2 } \multicolumn{1}{c}{ Distribution } & Statistic & & Distribution & Statistic \\
\hline Inverse Gaussian (3P) & 3.5855 & & Inverse Gaussian (3P) & 42.828 \\
Fatigue life (3P) & 3.7688 & & Burr (4P) & 49.312 \\
Burr (4P) & 4.0923 & & Log-gamma & 52.250 \\
Lognormal (3P) & 5.2669 & & Lognormal (3P) & 54.688 \\
Fatigue life & 5.7451 & & Fatigue life & 61.851 \\
\hline
\end{tabular}


EDI

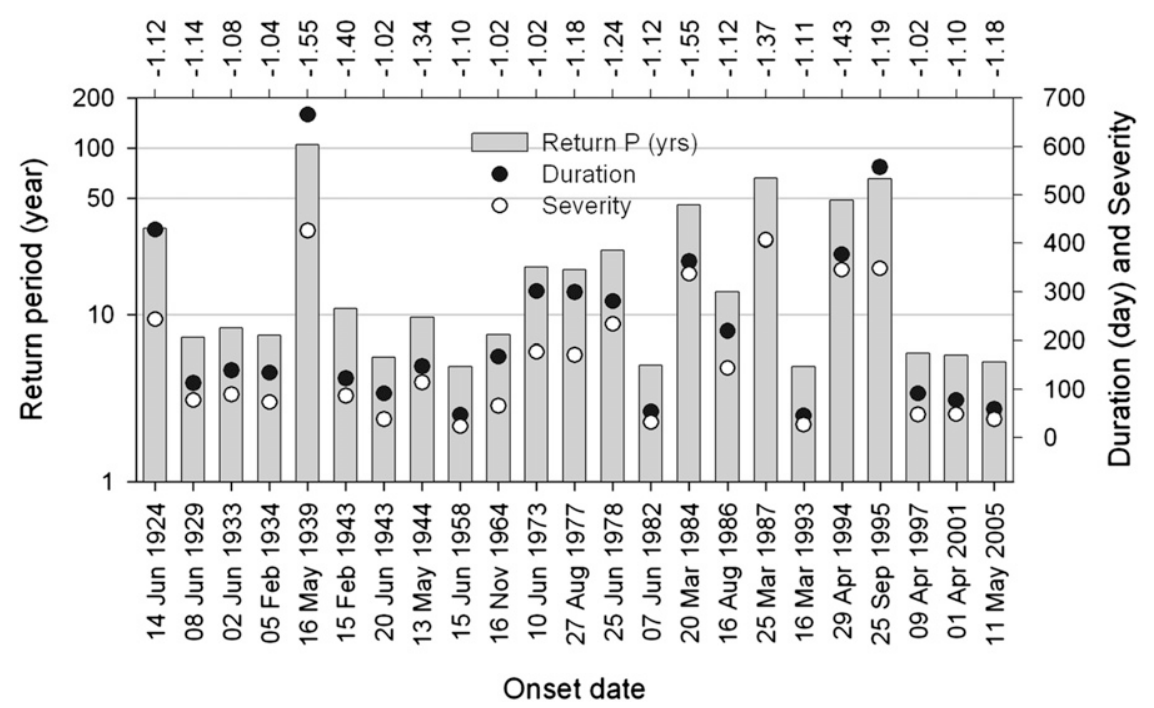

FIG. 10. Return periods, durations, severities, onset dates, and minimum EDI values of historical national droughts. Long-duration or high-intensity droughts have a longer return period.

than the drought in March 1984-March 1985 (minimum EDI of -1.55).

\section{Summary and conclusions}

In this study, rainfall data from 50 stations in Japan and the EDI were used to quantify the drought severity, and the drought climate over a 108 -yr period (i.e., 19022009) was analyzed.

In the country-wide analysis, 23 droughts with an EDI value below -1.0 were identified, whereas, at a regional level, 54, 54, 49, and 59 droughts were identified in groups $1-4$, respectively. Approximately $70 \%$ of the droughts were classified as short-term droughts that last less than 6 months and have an occurrence rate of 3.5 times per decade, and approximately $7 \%$ of the droughts were classified as long-term droughts that last for more than $1 \mathrm{yr}$ and have an occurrence rate of 0.3 times per decade. This predominance of short-term droughts is attributed to the three rainy seasons in Japan. We also found that the long-term droughts were caused by a rainfall deficit during the summer rainy season.

It was found that in G2-G4, short-term droughts occurred mainly in spring and summer, whereas in G1, the droughts were spread evenly over the year. The longterm droughts mainly occurred during the highest rainfall season (summer) in all the groups. Relief from drought came during the rainy season in all the groups, and in G1, drought relief came in winter owing to the melting snow. Differences in the drought occurrence associated with the mean rainfall were observed: G1 showed only one mean rainfall peak, whereas G2-G4 showed three mean rainfall peaks in a year.

The most striking feature of the spatiotemporal distribution analysis is that the drought climate of $\mathrm{G} 1$ is different from that of G2-G4. In addition, the 1950s and the 1990s were found to be the wettest and the driest decades, respectively. The country-wide average and regional average showed a continuous drying trend for $108 \mathrm{yr}$ and the late twentieth century was found to be the driest period. The sequential method using regime shift analysis showed four dry seasons (May 1994-November 1997, May 1939-May 1945, July 1977-May 1988, and May 2005-December 2009).

From the drought return period analysis, the May 1939-March 1941 drought was found to be the most extreme with a 104.7-yr return period. The March 1987May 1988 (minimum EDI of -1.37) and September 1995-April 1997 (minimum EDI of -1.19) droughts had return periods of 65.9 and $65.5 \mathrm{yr}$, respectively, and were evaluated to be even more extreme than the March 1984March 1985 drought (minimum EDI of -1.55).

Drought studies in Japan have rarely been conducted in the past. Therefore, this study provides the foundation data for reducing Japan's vulnerability to future droughts, investigating the causes of droughts, introducing measures to deal with future droughts, and reducing the perception that drought is not an issue in Japan.

Acknowledgments. This work was funded by the Korea Meteorological Administration Research and Development Program under Grant CATER 2006-2306. We 
thank Dr. F. Fujibe of the Meteorological Research Institute, Japan, for providing the daily precipitation data for Japan.

\section{REFERENCES}

Alley, W. M., 1984: The Palmer drought severity index: Limitations and assumptions. J. Climate Appl. Meteor., 23, 1100-1109.

Bhalme, H. N., and D. A. Mooley, 1981: Cyclic fluctuations in the flood area and relationship with the double (Hale) sunspot cycle. J. Appl. Meteor., 20, 1041-1048.

Bonaccorso, B., I. Bordi, A. Cancielliere, G. Rossi, and A. Sutera, 2003: Spatial variability of drought: An analysis of the SPI in Sicily. Water Res. Manage., 17, 273-296.

Byun, H. R., and D. A. Wilhite, 1999: Objective quantification of drought severity and duration. J. Climate, 12, 2747-2756.

_ S. J. Lee, S. Morid, K. S. Choi, S. M. Lee, and D. W. Kim, 2008: A study on the periodicities of droughts in Korea. AsiaPac. J. Atmos. Sci., 44, 417-441.

Chow, V. T., D. R. Maidment, and L. W. Mays, 1988: Applied Hydrology. McGraw-Hill, 570 pp.

Chowdhury, A., and V. P. Abhyankar, 1984: On some climatological aspects of drought in India. Mausam, 35, 375-378.

Cook, E. R., and G. C. Jacoby, 1983: Potomac River streamflow since 1730 as reconstructed by tree rings. J. Climate Appl. Meteor., 22, 1659-1672.

Dezfuli, A. K., M. Karamouz, and S. Araghinejad, 2010: On the relationship of regional meteorological drought with SOI and NAO over southwest Iran. Theor. Appl. Climatol., 100, 57-66, doi:10.1007/s00704-009-0157-2.

Eagleson, P. S., 1972: Dynamics of flood frequency. Water Resour. Res., 8, 878-898.

Gleick, P. H., G. Wolff, E. L. Chalecki, and R. Reyes, 2002: Globalization and international trade of water. The World's Water 2002-2003: The Biennial Report on Freshwater Resources, P. Gleick, Ed., Island Press, 33-56.

Guttman, N. B., 1998: Comparing the Palmer drought index and the standardized precipitation index. J. Amer. Water Resour. Assoc., 34, 113-121.

Haan, C. T., 1977: Statistical Methods in Hydrology. Iowa State University Press, 378 pp.

Heddinghaus, T. R., and P. Sabol, 1991: A review of the Palmer drought severity index and where do we go from here? Preprints, Seventh Conf. on Applied Climatology, Salt Lake City, UT, Amer. Meteor. Soc., 242-246.

Huff, F. A., and S. A. Changnon, 1963: Drought climatology of Illinois. Illinois State Water Survey Bull. 50, 68 pp.

IDI, 1998: Rivers in Japan 1998. Infrastructure Development Institute, Japan, Japan River Association, Tokyo, Japan. [Available online at http://www.adrc.asia/management/JPN/RIVERS\% 20IN\%20JAPAN\%201998.html.]

Japan Water Agency, cited 2010: Issues on water resources. [Available online at http://www.mlit.go.jp/tochimizushigen/ mizsei/water_resources/contents/issues.html.]

Jiang, T., Q. Zhang, D. M. Zhu, and Y. J. Wu, 2006: Yangtze floods and droughts (China) and teleconnections with ENSO activities (1470-2003). J. Int. Union Quat. Res., 144, 29-37.

Kang, K. A., and H. R. Byun, 2004: On the developing processes of the climatological drought over the East Asia in 1982. J. Kor. Meteor. Soc., 40, 467-483.

Karl, T. R., 1987: The sensitivity of the Palmer drought severity index and the Palmer Z-index to their calibration coefficients including potential evapotranspiration. J. Climate Appl. Meteor., 25, 77-86.
_ , and A. J. Koscielny, 1982: Drought in the United States: 18951981. J. Climatol., 2, 313-329.

— , and R. R. Heim, 1990: Are droughts becoming more frequent or severe in the United States? Geophys. Res. Lett., 17, 1921-1924.

Kim, D. W., H. R. Byun, and K. S. Choi, 2009: Evaluation, modification, and application of the effective drought index to 200-year drought climatology of Seoul, Korea. J. Hydrol., 378, $1-12$.

,,--- , and S. B. Oh, 2011: A spatiotemporal analysis of historical droughts in Korea. J. Appl. Meteor. Climatol., 50, 1895-1912.

Kim, T., J. B. Valdés, and C. Yoo, 2003: A nonparametric approach for estimating return periods of droughts in arid regions. J. Hydrol. Eng., 8, 237-246, doi:10.1061/(ASCE)1084-0699(2003)8:5(237).

Kim, Y. W., and H. R. Byun, 2006: On the causes of summer droughts in Korea and their return to normal. J. Kor. Meteor. Soc., 42, 237-251.

Klugman, M. R., 1978: Drought in the upper Midwest, 1931-1969. J. Appl. Meteor., 17, 1425-1431.

Lee, S. M., and H. R. Byun, 2009: Some causes of the May drought over Korea. Asia-Pac. J. Atmos. Sci., 45, 247-264.

Lloyd-Hughes, B., and A. M. Saunders, 2002: A drought climatology for Europe. Int. J. Climatol., 22, 1571-1592.

McKee, T. B., N. J. Doesken, and J. Kleist, 1993: The relationship of drought frequency and duration to time scales. Preprints, Eighth Conf. on Applied Climatology, Boston, MA, Amer. Meteor. Soc., 179-184.

Meko, D. M., C. W. Stockton, and T. J. Blasing, 1985: Periodicity in tree rings from the Corn Belt. Science, 229, 381-384.

Moon, Y., and U. Lall, 1994: Kernel quantile function estimator for flood frequency analysis. Water Resour. Res., 30, 3095-3103.

Morid, S., V. Smakhtin, and M. Moghaddasi, 2006: Comparison of seven meteorological indices for drought monitoring in Iran. Int. J. Climatol., 26, 971-985.

Murata, A., 1990: Regionality and periodicity observed in rainfall variations of the Baiu season over Japan. Int. J. Climatol., 10, 627-646.

Palmer, W. C., 1965: Meteorological drought. Weather Bureau Research Paper 45, Department of Commerce Washington, DC, 58 pp.

Pandey, R. P., B. B. Dash, S. K. Mishra, and R. Singh, 2007: Study of indices for drought characterization in KBK districts in Orissa (India). Hydrol. Processes, 22, 1895-1907, doi:10.1002/ hyp.6774.

Rodionov, S. N., 2006: The use of prewhitening in climate regime shift detection. Geophys. Res. Lett., 33, L12707, doi:10.1029/ 2006GL025904.

Shiau, J. T., and H. W. Shen, 2001: Recurrence analysis of hydrologic droughts of differing severity. J. Water Resour. Plan. Manage., 127, 30-40.

Silverman, B. W., 1986: Density Estimation for Statistics and Data Analysis. Chapman and Hall, $175 \mathrm{pp}$.

Smakhtin, V. U., 2001: Low flow hydrology: A review. J. Hydrol., 240, 147-186.

Sönmez, F. K., A. U. Komuscu, A. Erkan, and E. Turgu, 2005: An analysis of spatial and temporal dimension of drought vulnerability in Turkey using the standardized precipitation index. Nat. Hazards, 35, 243-264.

Soulé, P. T., 1993: Hydrologic drought in the contiguous United States, 1900-1989: Spatial patterns and multiple comparisons of means. Geophys. Res. Lett., 20, 2367-2370.

Takahashi, Y., and Y. Sakaguchi, 1976: Rivers in Japan (in Japanese). Kagaku, 46, 488-499. 
Takahasi, Y., 2009: History of water management in Japan from the end of World War II. Water Resour. Develop., 25, 547553.

, and J. I. Uitto, 2004: Evolution of river management in Japan: From focus on economic benefits to a comprehensive view. Global Environ. Change, 14A, 63-70, doi:10.1016/j.gloenvcha. 2003.11.005.

Taniyama, S., 2002: Water resources and rice paddy cultivation in the Asia monsoon region. Japanese National Committee of International Commission on Irrigation and Drainage, 19 pp. [Available online at http://www.bvsde.paho.org/bvsacd/ dialogo/taniyama.pdf.]

Trnka, M., M. Dubrovsky, M. Svoboda, D. Semeŕadov'a, M. Hayes, Z. Zalud, and D. Wilhite, 2009: Developing a regional drought climatology for the Czech Republic. Int. J. Climatol., 29, 863-883.
Uemera, K., Y. Mihara, J. Hanyu, and Y. Omoto, 1974: Meteorological hazards. Agricultural Meteorology of Japan, Y. Mihara, Ed., University Press of Hawaii, 97-125.

Wang, X. W., H. J. Xie, H. D. Guan, and X. B. Zhou, 2007: Different responses of MODIS-derived NDVI to root-zone soil moisture in semi-arid and humid regions. J. Hydrol., 340, 1224, doi:10.1016/j.jhydrol.2007.03.022.

Wilhite, D. A., 1983: Measuring drought severity and assessing impact. Int. Symp. on Hydrometeorology, Denver, CO, American Water Resources Association, 333-335.

Willems, P., 2000: Compound intensity/duration/frequency relationships of extreme precipitation for two seasons and two storm types. J. Hydrol., 233, 189-205.

Yamamoto, S., 1995: Recent trend of land subsidence in Japan. Proc. Fifth Int. Symp. on Land Subsidence, The Hague, Netherlands, IAHS Publ. 234. 